\title{
Philosophiques
}

\section{Patriotisme constitutionnel et identité nationale}

\section{Dominique Leydet}

Volume 19, numéro 2, automne 1992

Une nation peut-elle se donner la constitution de son choix?

URI : https://id.erudit.org/iderudit/027193ar

DOI : https://doi.org/10.7202/027193ar

Aller au sommaire du numéro

Éditeur(s)

Société de philosophie du Québec

ISSN

0316-2923 (imprimé)

1492-1391 (numérique)

Découvrir la revue

Citer ce document

Leydet, D. (1992). Patriotisme constitutionnel et identité nationale. Philosophiques, 19(2), 81-92. https://doi.org/10.7202/027193ar d'utilisation que vous pouvez consulter en ligne.

https://apropos.erudit.org/fr/usagers/politique-dutilisation/ 


\title{
PATRIOTISME CONSTITUTIONNEL
}

\author{
ET IDENTITÉ NATIONALE
}

\author{
par \\ Dominique Leydet
}

Le psychodrame canadien et québécois présente un cas passionnant à la philosophie politique contemporaine car s'y pose concrètement le double problème de l'expression de l'identité collective et de son intégration au sein d'un tout politique où doivent cohabiter une multiplicité de telles identités. Les discussions actuelles reflètent cet entremêlement des domaines de la culture et du juridico-politique. La question choisie par Lukas Sosoe et Michel Seymour comme theme de ce Colloque: « Une nation peut-elle se donner la constitution de son choix? » implique elle-même ce chevauchement, puisque le terme de nation renvoie à l'existence d'une communauté de culture et d'histoire, alors que l'usage du concept de constitution nous ramène à l'entité du juridico-politique. Or, la question qui se pose aujourd'hui au Canada et au Québec, mais j'ajouterais dans toutes les sociétés avancées, est de savoir comment on peut allier ainsi la culture au cadre juridico-politique.

Bien sûr, ces deux niveaux se retrouvent conjugués dans le concept d'État-nation, lequel présuppose, grosso modo, une adéquation entre l'organisation de l'Etat et une nation déterminée, où l'Etat est considéré comme le porteur de l'identité collective nationale constituée à partir d'une histoire, d'une langue et d'une culture communes. Depuis longtemps déjà, défenseurs et détracteurs de ce modèle écument l'histoire récente, et singulièrement les nouvelles réalités européennes, afin de signifier soit le caractère indépassable, soit l'acte de décès de cet idéal. Mais la 
question est alors mal posée, puisque l'État-nation homogène a toujours été dans les faits une fiction, recouvrant un mode d'intégration où les diverses minorités doivent être, bon gré mal gré, assimilées au tissu national et soumises à l'administration centrale. Ce mode d'intégration est aujourd'hui impensable dans des sociétés travaillées, de l'intérieur, par un pluralisme de fait, de l'extérieur, par les exigences d'intégration supra-nationale posées par une interdépendance croissante. Autrement dit, nos sociétés n'ont plus ni les moyens, ni même la volonté - étant donné la reconnaissance accrue des valeurs démocratiques d'utiliser un tel modèle d'intégration.

Mais, parce qu'il serait également dérisoire de nier la permanence du besoin identitaire ressenti par les communautés et par les individus qui en sont membres (la vigueur des sentiments nationaux en Europe en fait foi), la question de l'identité collective demeure entière.

Ce double problème de l'identité et de l'intégration se pose selon deux perspectives distinctes, mais complementaires: si tout État renferme en ses frontières une pluralitè de communautés historiques, comment penser l'intégration de ces communautés, possédant chacune une identité collective distincte, à l'intérieur du tout national? Par ailleurs, quelle place assigner, quelle reconnaissance institutionnelle donner à la communauté dominante à l'intérieur de cet Etat? Son identité collective propre peut-elle constituer le coeur de l'identité nationale?

Jaimerais aborder ces questions à partir de quelques textes récents de Jürgen Habermas, rédigés à l'occasion du débat des historiens ayant fait rage dans les annees 80 , puis de l'unification rapide des deux Allemagnes ${ }^{1}$. Ces textes méritent notre attention parce qu'ils montrent à quoi engage pratiquement la conception qu'a Habermas d'une certaine universalité des normes et quels types de problemes l'application de cette conception suscite dans un contexte politique et historique déterminè.

Que la pensée de Habermas en soit restee à l'ètat d'ébauches, composées sur le vif des événements, ne doit pas nous arrêter. Au contraire, il me semble important de choisir cette pensée

1. Voir Jürgen Habermas, Kleine politische Schriften VI, Frankfurt am Main, Suhrkamp, 1987, Jürgen Habermas, Kleine politische Schriften VII (Die nachholende Revolution), Frankfurt am Main, Suhrkamp, 199o. Trad. franç. (partielle): Ecrits politiques, trad. par Ch. Bouchindhomme et R. Rochlitz, Paris, Cerf, I9go. Les principales pièces de la controverse des historiens ont été rassemblees et traduites dans: Devant l'histoire, Paris, Cerf, 1988. 
comme guide de notre réflexion, quitte à l'étayer, pour répondre en son nom à des objections qu'elle ne considère pas, parce qu'elle a pour mérite insigne de prendre pour prémisse ce fait incontestable des sociétés modernes, à savoir le pluralisme.

\section{QU'EST-CE QUE LE PATRIOTISME CONSTITUTIONNEL?}

Ce qu'il est convenu d'appeler le Historikerstreit désigne la polémique suscitée dans les années 80 par les écrits de certains historiens défendant le projet de la restauration d'une identité nationale allemande " normale », à l'aide d'une historiographie renouvelée qui présenterait un récit cohérent et continu de l'histoire du peuple allemand. Une telle narration, pour être possible, exigeait cependant que l'on reconsidère la place et le sens de la période nazie dans l'histoire allemande. En bref, le régime hitlérien ne devait plus signifier une rupture radicale, une catastrophe unique exigeant la profonde remise en cause des traditions, mais un épisode réinsérable, et même, jusqu'à un certain point, rèhabilitable au sein de l'histoire et de l'identité allemandes. Rejoignant ici le noeud de sa critique de l'herméneutique gadamérienne et du néoaristotélisme, Habermas devait dénoncer un tel projet au nom de ce qu'il considère être la leçon d'Auschwitz, leçon dont la portée dépasse de loin le contexte allemand.

Auschwitz, pour Habermas, c'est le symbole de l'impossibilité de conserver une attitude confiante devant la tradition, c'est la nécessité d'assumer une attitude réfléchie et critique vis-à-vis des continuités nationales ${ }^{2}$. Toute tradition possède, en effet, sa face cachée, obscure et la tâche de l'historiographie ne doit pas être de gommer ces aspérités, de glisser sur les épisodes gênants afin de constituer une hagiographie de la communauté à laquelle viendrait se nourrir l'identité collective, mais plutôt de constituer ce que Habermas appelle une "conscience problématisée de l'histoire ${ }^{3}$, se nourrissant du conflit des interprétations du passé.

Il y a, par conséquent, dans ce rejet d'une identité collective constituée à partir d'une histoire nationale « commune »un motif moral. C'est là un point essentiel de la pensée proprement philosophique de Habermas. Rappelons-nous son insistance à condamner la réhabilitation du préjugé énoncée par Gadamer, sa revendication de l'héritage critique des Lumières, enfin, son

2. Ecrits politiques, Op. cit., p. 228.

3. Ibid., p. 235 . 
élaboration d'une éthique reprenant à son compte la visée formelle et universaliste du criticisme kantien.

Cela dit, Habermas veut aussi montrer comment cet argument moral se trouve confirmé par les faits eux-mêmes. Aujourd'hui, écrit-il: « le retour à une identité qui se constitue à partir de l'histoire nationale, est une démarche qui, du moins dans les sociétés occidentales, ne nous est plus permise ${ }^{4}$. Habermas explicite sa position en référence aux deux éléments principaux qui constituent l'identité propre à l'État national démocratique issu de la Révolution française, soit, premièrement, les principes axiologiques à vocation universelle qui sont au fondement du républicanisme, soit l'État de droit et la démocratie; deuxièmement, « les particularismes en fonction desquels la nation se démarque de l'extérieur $»^{5}$. Historiquement, ces deux éléments se sont maintenus, dans les États-nations classiques, en un équilibre relatif et ce n'est qu'en Allemagne que le nationalisme dégénéra dans la folie raciale du national-socialisme. Or, pour Habermas, l'évolution récente de l'Allemagne fédérale et des autres Etats européens témoigne d'un glissement dans le rapport entre ces deux éléments au profit de l'universalisme.

Cette tendance s'explique essentiellement par la relativisation des formes de vie à laquelle conduit le pluralisme culturel. Ce pluralisme est d'abord le produit, c'est là un lieu commun, de ces grands déplacements de population qui ont marqué notre siècle. «Qu'ils aient eu pour cause la guerre, l'oppression politique, la misère économique ou le marché international du travail », ces mouvements, écrit Habermas, n'auront « laissé aucune des sociétés développées inchangées dans leur composition ethnique $»$. Or ces communautés ethniques qui composent une part croissante de la population de nos sociétés peuvent difficilement se retrouver dans une identité qui se constituerait essentiellement à partir d'une histoire, de traditions qui leur sont étrangères. Le « nos ancêtres les Gaulois » ânonné par de petits Africains n'a guère de sens aujourd'hui. Il en a d'autant moins, et c'est un autre lieu commun, que le développement des communications, le tourisme de masse, la perte de sens des institutions traditionnelles favorisent la conscience, qu'elle soit naïve ou simpliste, de traditions autres. Une telle conscience

4. Ibid., p. 229

5. Ibid., p. 230 .

6. Ibid., p. 234. 
entraîne une relativisation de nos propres formes de vie, qui ne représentent plus qu'un choix possible parmi d'autres ${ }^{7}$.

Par ailleurs, l'évolution qu'ont connue les sciences historiques les rend de moins en moins aptes à jouer leur rôle traditionnel dans le processus de mise en sens et de mise en forme publique de la tradition nationale et les conduit beaucoup plus à la « problématisation de la conscience de l'histoire qu'à la constitution de l'identité et la fondation du sens $\gg$.

En somme, les sociétés modernes nous présentent de plus en plus l'image d'un maelström dans lequel se chevauchent une multiplicité d'identités collectives qui se nourrissent de traditions culturelles différentes. Cette multiplicité, et la relativisation des formes de vie qu'elle suscite, interdisent de penser que l'intégration dans l'État puisse se faire à partir d'une tradition historique nationale.

Si le second élément de l'État national démocratique ne peut plus constituer une solution viable à la question de l'identité collective, reste l'élément axiologique. De fait, écrit Habermas, « plus est importante la manière dont, dans leur multiplicité discordante, des formes de vie distinctes, concurrentes, s'exploitent mutuellement, exigent leur droit à la coexistence et à l'égalité de traitement, et plus il est clair qu'il n'y a plus d'autres solutions que l'extension de la conscience morale dans une direction universaliste $\gg^{9}$. Or, c'est dans le contrat politique au fondement de tout État démocratique que peut s'institutionnaliser, s'effectuer cette conscience morale. Par consequent, l'identité collective post-nationale, post-conventionnelle doit se réaliser dans ce que Habermas nomme le « patriotisme constitutionnel ».

Ainsi, au lieu de s'édifier à partir de données qualifiées par Habermas de « pré-politiques $\gg^{16}$, telles que la langue, la culture, l'histoire, cette identité post-conventionnelle doit se construire à partir d'un projet politique, affirmant comme fondateur de l'espace commun les principes universels des Droits de l'homme et la notion d'État de droit.

Tout ceci explique les prises de position de Habermas lors des événements ayant mené à l'unification accélérée des deux Allemagnes. Habermas s'est, en effet, opposé avec force à ce que

7. Ibid., p. 238 .

8. Ibid., p. 235 .

9. Ibid., p. 235.

10. Die nachholende Revolution, Op.cit., p. 208. 
l'on procède à l'union politique au travers de l'article 23 de la loi fondamentale, c'est-à-dire que l'on considère l'unification comme une simple addition de nouveaux Länder. Vous le savez, la loi fondamentale qui tient lieu de constitution à l'Allemagne fédérale est explicitement provisoire, l'intention des pères fondateurs de la Bundesrepublik ayant été qu'au jour de l'unification, cette loi fondamentale laisse la place à une nouvelle constitution représentant la volonté collective de tous les Allemands. Pour Habermas, procéder à une unification rapide par l'entremise de l'article 23, C'était renoncer à la possibilité d'effectuer l'intégration des Allemands de l'Ouest et de l'Est au sein du nouvel Etat à partir d'une discussion ouverte des principes devant constituer les fondements du nouveau tout politique. Cétait négliger de construire une identité nationale à partir d'une conscience éclairée de ces principes, en pariant paresseusement et cyniquement sur la force d'attraction du Mark et sur des solidarités pré-politiques, dont on peut constater aujourd'hui le caractère également aléatoire. C'était, enfin, risquer de retomber dans la vieille ornière de l'idéologie allemande où la question nationale s'émancipe des principes republicains.

Quelle que soit la justesse ou la naïveté de ces convictions, ce qu'il importe de souligner ici c'est à quel point Habermas entend bien situer la question de l'identité nationale, non plus dans la sphère de la culture, mais dans le champ juridicopolitique.

\section{RÉPONSES À QUELQUES OBJECTIONS}

On pourrait être d'accord en principe avec l'analyse de Habermas tout en ne pouvant croire que le patriotisme constitutionnel représente une réponse possible ou même pensable à la question de l'identité collective. Permettez-moi d'aborder deux types de problèmes posés par la réflexion de Habermas. Premièrement, le patriotisme constitutionnel peut-il constituer une identité collective authentique? Comme le signalait Jean-Marc Ferry dans une entrevue que lui accordait Habermas en I988, «ce qui est en question, c'est la force d'identification et de motivation que peuvent posséder des prétentions à la validité purement formelles et universalistes ${ }^{\mathrm{II}}$. Deuxièmement, il n'est pas

II. "Grenzen des Neohistorismus ", in Die naccholende Revolution, P. 153. Toutes les citations tirées de cet ouvrage sont nos traductions. (Une version française partielle de cet entretien est parue dans Globe, $\mathrm{n}^{\circ}$ 30, juil.- août 1988, sous le titre « L'Allemagne, la memoire et l'histoire ».) Voir 
sûr que ce patriotisme constitutionnel puisse composer avec un pluralisme radical, avec ce que Charles Taylor, critiquant le " patriotisme de la Charte » de certains fédéralistes, appelait la «diversité profonde ${ }^{12}$. L'universalisme normatif de Habermas n'est-il pas un cadre trop rigide et finalement inacceptable pour qui veut confronter la réalité du pluralisme?

Revenons à notre première question. « Comment l'option radicalement universaliste du 'patriotisme constitutionnel' peutelle offrir une force constitutive d'identité, qui n'implique pas seulement une légitimité morale, mais aussi une plausibilité historique? $\gg^{13}$. En réponse à cette interrogation de Jean-Marc Ferry, Habermas se défend de vouloir simplement substituer à un type d'identité nationale enraciné dans une histoire, dans une culture déterminée un modèle universaliste abstrait. De fait, Habermas pratique une distinction entre les principes universels abstraits, qu'il convient de reconnaitre au fondement du projet politique de toute société moderne, et le « patriotisme constitutionnel » dans lequel ces principes se donnent une expression concrète, propre à une société déterminée. Car il n'est pas question pour Habermas de nier le fait que toute identité, qu'elle soit individuelle ou collective, est toujours quelque chose de concret, de particulier ${ }^{14}$. Les principes démocratiques ne peuvent devenir réalité dans une socièté donnée que si ces principes s'y enracinent d'une façon spécifique. Habermas écrit ainsi: "Toute identité collective, y compris l'identité post-nationale, est beaucoup plus concrète que l'ensemble des principes moraux, juridiques et politiques autour desquels elle se cristallise ${ }^{15}$. Par exemple, l'identité post-nationale allemande différerait de celle de la France, étant donné les modes divergents par lesquels les principes démocratiques se sont historiquement effectués dans ces deux pays.

Ainsi, la position de Habermas concernant la référence à une tradition historique se précise-t-elle. Habermas nie que l'identité collective d'une socièté pluraliste puisse se constituer

également l'analyse de Ferry du patriotisme constitutionnel dans son ouvrage Les puissances de lexperience, Paris, Cerf, 1991, vol. 2, Pp. I87-196.

12. Voir Charles Taylor, «Shared and Divergent Values », in R. LWatts, D. M. Brown (eds), Options for a New Canada, Toronto, University of Toronto Press, Iggi.

13. Die nachholende Revolution, Op.cit., p. 153.

14. Ibid., p. I5I.

15. Ibid., p. 154. 
à partir de la tradition propre à une forme de vie particulière, laquelle fonctionnerait comme le coeur de cette identité. Ce rôle doit être aujourd'hui tenu par des principes abstraits comme les Droits de l'homme, mais qui se nourrissent à la source des traditions culturelles, politiques consonantes. En d'autres termes, ce que Habermas vise ce n'est rien de moins qu'un « universel concret », nouvelle manière. Ėcoutons Habermas: D'une part, écrit-il, « (l)'attachement à ces principes supposé par le patriotisme constitutionnel doit en vérité se nourrir de l'héritage consonant à des traditions culturelles ». Cela dit, les formes de vie diverses et les identités collectives qui leur correspondent « n'ont plus besoin », ajoute Habermas, "d'un centre à partir duquel elles seraient agrégées et intégrées à l'identité nationale. $\mathrm{Au}$ lieu de cela, c'est l'idée abstraite d'universalisation de la démocratie et des Droits de l'homme qui constitue le matériau solide sur lequel vient se réfracter le rayonnement des traditions nationales - du langage, des traditions et de l'histoire de chaque nation propre ${ }^{16}$.

La réponse de Habermas à Ferry tient donc en deux points: l'identité post-nationale ne prétend pas éliminer les identités collectives particulières, fondees sur une langue, une culture et une histoire communes. Simplement, il est reconnu impossible, dans les sociétés modernes pluralistes, d'ériger une de ces identités collectives particulières en conscience nationale. Cette place doit être occupée par les principes universels des Droits de l'homme et de l'Etat de droit, dans la forme qui leur est propre au sein d'une culture politique déterminée. Aussi, n'est-il pas question d'exiger du patriotisme constitutionnel qu'il recèle pour les individus la même force d'identification et de motivation qu'exerce une identité culturelle particulière. Car il ne s'agit pas de choisir entre ces deux identités, mais de penser leur complémentarité.

Seulement voilà, et j'en arrive ainsi au second problème évoqué plus haut, ce modèle présuppose, pour reprendre l'expression de Habermas, des héritages culturels consonants. En d'autres termes, on suppose, d'une part, que les identités collectives, correspondant à diverses formes de vie, ne sopposent pas aux principes universels. Or, on peut aisément évoquer des communautés pour lesquelles ces principes demeurent étrangers et incompatibles avec leurs valeurs propres. Ainsi, la

16. Ecrits politiques, Op. cit., p. 238. 
séparation de l'Église et de l'Etat, plus généralement la laïcité, apparaissent à un intégriste musulman comme une violence absurde et intolérable. D'autre part, la forme particulière que prennent ces principes doit être acceptable à toutes les communautés présentes dans l'État démocratique. Or, il est possible que des communautés reconnaissant la légitimité de ces principes fondamentaux, mais ne partageant pas entièrement une même culture politique, divergent quant à la façon de concevoir l'expression concrète de ces principes. Ce second type de diversité expliquerait, si l'on suit l'analyse de Charles Taylor ${ }^{17}$, l'incompréhension persistant entre des Canadiens anglais de plus en plus attachés à une version strictement individualiste de la tradition libérale et des Québécois francophones ${ }^{18}$ se rèclamant d'un libèralisme qui n'exclut pas les projets collectifs au contenu substantiel, comme celui de l'épanouissement de la langue et de la culture françaises. Le modèle propose par Habermas peut-il nous permettre de mieux penser ces diversités radicales? Devronsnous convenir, au contraire, qu'elles le mettent en échec?

Le premier type de diversité radicale semble récuser la prétention à l'universalité de principes tels que les Droits de l'homme, prétention qui justifie, en dernière instance, le projet de Habermas. Rappelons d'emblée que les notions de ce type sont dites universelles non pas parce qu'elles constituent effectivement des principes auxquels adhèrent, de façon implicite ou explicite, toutes les cultures, mais bien parce qu'elles sont prétendues " universalisables ». Certes, ces notions sont issues d'une culture, d'une histoire déterminée. De même, il est indéniable, par exemple, que la déclaration des Droits de l'homme n'a

17. Charles Taylor, Op. cit.

18. Lors du Colloque, Christian Dufour m'a reproché cet usage du terme "Québécois francophones », lequel contredirait le projet politique impliqué dans la notion de " société distincte ». Ce concept exprimerait, en effet, un depassement du nationalisme à base ethnique ou plus strictement culturel, pour viser l'élaboration d'une volonté politique québécoise englobant cette fois l'ensemble des communautés culturelles en sol québécois. Je suis entièrement d'accord avec ce projet comme en témoigne, je l'espère, l'ensemble de ma conférence. Je persiste cependant à utiliser ici l'expression «Québécois francophones » précisément parce que cette tâche énoncée par Christian Dufour n'est pas réalisèe et qu'une bonne part de la minorité anglophone du Québec, loin de se reconnaitre dans ce projet, se retrouve beaucoup plus dans la culture politique libérale d'inspiration américaine. En somme, je pense qu'il est prématuré de vouloir, au fond, gommer la différence, selon moi bien réelle, existant entre les cultures politiques au Québec. 
pas empêché que soient longtemps exclus de leur protection les races non blanches, les femmes, les pauvres. Reste que ces principes ne sont pas exclusifs, mais essentiellement inclusifs; le cadre normatif qu'ils forment peut être élargi à l'humanité toute entière. On ne saurait en dire autant de valeurs qui sont essentiellement et explicitement liées à une ethnie, à une religion données. En ce sens, les principes au fondement de la démocratie sont à même de dessiner l'espace commun dans lequel pourraient cohabiter des communautés aux traditions par ailleurs divergentes. Mais cela implique que ces principes constituent un fondement que l'on ne saurait marchander, qu'ils tracent, en fait comme en droit, les limites du pluralisme. Cela ne signifie pas que toutes les communautés doivent se reconnaitre dans un même mode d'effectuation de ces principes. Une certaine flexibilité demeure possible et justifiable. Toutefois, les modalités d'une telle flexibilité ne peuvent être déterminées au niveau des principes; elles relèvent de négociations politiques.

Cela dit, à quoi nous engage concrètement la reconnaissance du caractère fondamental, indépassable de ces principes universalistes? Elle nous engage à affirmer clairement leur préséance sur tout autre projet collectif. Cela ne veut pas dire que seul un libéralisme à l'américaine soit légitime. La culture politique canadienne s'est traditionnellement démarquée de cet individualisme américain. La Charte canadienne des droits et libertés ellemême témoigne de cette tradition communautaire. J'en veux pour preuve l'article i et certains arrêts clefs de la Cour (par exemple concernant l'affaire Keegstra). Dans ce contexte, il devrait être possible de concilier aux principes de la charte, la volonté collective des francophones d'accorder un statut spécial au français. Mais la possibilité d'une telle conciliation demeure fragile, vulnérable notamment à un changement dans l'équilibre idéologique de la Cour elle-même. Cette inquiétude pourrait être calmée, toutefois, si l'on reconnaissait plus explicitement cette spécificité canadienne en adoptant, par exemple, comme clause interprétative de la Charte, la notion de société distincte pour le Québec et un concept analogue pour les communautés autochtones $^{\text {19 }}$.

19. Il n'est pas du tout sùr que ce serait là un moyen suffisant d'empêcher une dérive " américanisante » de la Cour. D'autres moyens peuvent être et sont envisagés. Je n'ai avancé cette possibilité de solution qu'à titre d'illustration. 
Mais, ce qui serait irrecevable, cest, par exemple, que la Charte canadienne des droits et libertés ne puisse être invoquée par des membres des nations autochtones ou encore que, dans l'éventualité d'un Québec souverain, on ne reconnaisse pas la préséance ultime de la Charte québécoise des droits et libertés sur la Charte de la langue française. Ce dernier point peut sembler trivial, mais il est essentiel.

Le patriotisme constitutionnel de Habermas implique une distanciation entre l'État, c'est-à-dire la sphère du juridico-politique et la culture. L'État post-national ne peut être considéré comme porteur de l'identité collective particulière d'une nation déterminée. Si l'on veut proposer un projet collectif auquel pourront s'identifier la pluralité des communautés appartenant à notre société, on doit renoncer à présenter l'État comme l'expression politique d'une culture donnée. Cette réflexion vaut, bien sûr, pour le Canada, elle vaut aussi pour le Québec où les communautés immigrantes d'origines non Européennes sont de plus en plus importantes. Comme l'écrivait Jürgen Habermas: «Une identité nationale qui ne s'appuie pas d'abord sur une compréhension de soi républicaine procédant d'un patriotisme constitutionnel, heurte les règles universalistes ordonnant le vivre-ensemble des formes de vie coexistantes et également légitimes $»^{20}$.

Encore une fois, cela ne signifie pas qu'il soit illégitime pour le gouvernement du Québec de vouloir protéger et travailler à l'épanouissement de la langue française, dans le cadre d'une société « libre et démocratique ». Seulement, il serait illusoire de croire que ce projet, conçu dans les termes d'une conscience identitaire propre à une communauté historique déterminée, puisse jouer un rôle intégrateur dans un contexte pluraliste. En ce sens, tout comme le Canada, le Québec, souverain ou non, ne saurait faire l'économie du «patriotisme constitutionnel $»^{2 \mathrm{I}}$.

Département de philosophie

Université d'Ottawa

20. Die nachholende Revolution, Op. cit., p. 217.

21. Au cours du Colloque, plusieurs critiques, souvent virulentes, ont été adressées au rôle fondamental reconnu au principe d'une charte des droits et libertés enchâssée dans la Constitution (que ce soit au Canada 
ou dans un Québec souverain). Je pense notamment à la conférence et aux interventions des professeurs Joseee Legault et Gary Caldwell. Jaimerais signaler deux points, dans le contexte précis du projet de patriotisme constitutionnel défendu ici. Tout d'abord, ce projet n'est pas intrinsèquement liè à l'idèe d'une Charte enchâssée dans la Constitution, laquelle pose, il est vrai, de nombreux problèmes, dont celui d'une judiciarisation à outrance du politique. Il se pourrait qu'une telle Charte, singulièrement la Charte canadienne, ne soit pas le meilleur moyen d'effectuer les principes des Droits de l'homme et de l'Etat de droit. Cela dit, un tel constat, s'il était fait, ne suffit pas en lui-même, puisque demeure la nécessité de penser et d'ancrer une identité post-nationale, post-conventionnelle. En tout etat de cause, l'appel à de simples considérations tactiques ne saurait suffire. 